\title{
Where to spot: individual identification of leopard cats (Prionailurus bengalensis euptilurus) in South Korea
}

\author{
Heebok Park ${ }^{1}$, Anya Lim² ${ }^{*}$, Tae-Young Choi ${ }^{2}$, Seung-Yoon Baek ${ }^{3}$ Eui-Geun Song ${ }^{4}$ and Yung Chul Park ${ }^{1 *}$
}

\begin{abstract}
Knowledge of abundance, or population size, is fundamental in wildlife conservation and management. Cameratrapping, in combination with capture-recapture methods, has been extensively applied to estimate abundance and density of individually identifiable animals due to the advantages of being non-invasive, effective to survey wideranging, elusive, or nocturnal species, operating in inhospitable environment, and taking low labor. We assessed the possibility of using coat patterns from images to identify an individual leopard cat (Prionailurus bengalensis), a Class II endangered species in South Korea. We analyzed leopard cat images taken from Digital Single-Lense Relfex camera (high resolution, 18Mpxl) and camera traps (low resolution, 3.1 Mpxl) using HotSpotter, an image matching algorithm. HotSpotter accurately top-ranked an image of the same individual leopard cat with the reference leopard cat image $100 \%$ by matching facial and ventral parts. This confirms that facial and ventral fur patterns of the Amur leopard cat are good matching points to be used reliably to identify an individual. We anticipate that the study results will be useful to researchers interested in studying behavior or population parameter estimates of Amur leopard cats based on capture-recapture models.
\end{abstract}

Keywords: Leopard cat, Photo identification, Coat pattern, Image matching, Natural marking, Prionailurus bengalensis

\section{Background}

Abundance, or population size, is a primary parameter in wildlife conservation and management used to prioritize conservation actions and assess the conservation effectiveness (Seber 1973; McCarthy et al. 2008; Jenks et al. 2011; Jones 2011; Rovero et al. 2014). Camera-trapping, in combination with the traditional capture-recapture or spatially explicit capture-recapture methods, has been widely applied to estimate the absolute abundance of individually identifiable species (Seber 1973; Nichols 1992; Karanth et al. 2004; Royle and Young 2008; Russell et al. 2012; Karki et al. 2013; Avgan et al. 2014; Qi et al. 2015; Linden et al. 2017). The camera-trapping is efficient for surveying wide-ranging, cryptic and elusive animals in inhospitable environment such as tropical rainforest (Tobler et al. 2008, Rovero et al.

\footnotetext{
* Correspondence: anya@nie.re.kr; parky@kangwon.ac.kr

${ }^{2}$ Research Center for Endangered Species, National Institute of Ecology, Yeongyang 36531, Republic of Korea

'Wildlife Research Lab, Kangwon National University, Chuncheon 24341, Republic of Korea

Full list of author information is available at the end of the article
}

2014). Unlike many survey techniques, it is non-invasive, thereby reducing observer bias and influence on animal's behavior and requires less manpower (Gompper et al. 2006, Alonso et al. 2015, Caravaggi et al. 2017). Natural body markings, such as stripes, spots, and blotches, from camera trap photos are some indicators to identify individuals (Sharma et al. 2013; Boron et al. 2016; Mettouris et al. 2016). Therefore, the capture-recapture method using camera trap images for estimation of population size has primarily targeted big cats with distinctive coat patterns such as tigers (Panthera tigris), leopards (Panthera pardus), jaguars (Panthera onca), and snow leopards (Panthera uncia) (Karanth and Nichols 1998; Henschel and Ray 2003; Cullen et al. 2005; Soisalo and Cavalcanti 2006; Maffei and Noss 2008; McCarthy et al. 2008; Lynam et al. 2009). However, natural body markings include not only coat patterns but also whisker spot patterns and permanent scars (Creel and Creel 1997; Anderson et al. 2007; Osterrieder et al. 2015).

As monitoring technology using camera traps improved, individual identification of small carnivores 
including leopard cats (Prionailurus bengalensis bengalensis) in South Asia and American martens (Martes americana) in the USA, became also feasible (Bashir et al. 2013; Sirén et al. 2016). However, compared to leopard cats in South or Southeast Asia, adult Amur leopard cats (P. b. euptilurus) in East Asia have dim fur patterns on flanks, which makes photo-identification extremely difficult. The Amur leopard cat is a Class II endangered species in South Korea (Ministry of Environment 2011) while leopard cats are generally least concerned in most other countries (Ross et al. 2015). However, very little is known about its population and behavior (Park et al. 2017), and capture-recapture method has not been applied yet to estimate the population. Therefore, we aimed to test whether the Amur leopard cat has natural body markings to develop a reliable noninvasive identification system for use in studies of behavior and population parameter estimates.

\section{Methods}

In order to identify reliable natural markings, we analyzed Amur leopard cat images from two different sources-facial images of seven captive individuals in two wildlife rescue centers, Gyungnam Wildlife Rescue Center and Korean Avian Conservation Society in Cheolwon, in South Korea, taken with high-resolution (18 Mpxl) Digital Single-Lense Relfex cameras (EOS 7D, Canon Inc, DSC-HX400V, Sony Inc.), and images of 11 wild individuals taken with low- resolution (3.1 Mpxl) camera traps (Reconyx HC550). To acquire wild leopard cat images, we deployed 16 camera traps in two different riparian parks, Hwapocheon in Gimhae and Eulsukdo in Busan between May and November 2015 (8 camera traps per riparian park, Fig. 1). To increase detection rate, we placed a lure stick scented with Valerian oil in front of the camera traps (Burki et al. 2010; Anile et al. 2012; Steyer et al. 2013) (Fig. 2). We selected a total of 11 high-resolution images of 7 captive leopard cats (4 females and 3 males) and 15 low-resolution images of 11 wild leopard cats (sex undetermined) that contained less noise and clutter among the 63 low-resolution images that we obtained. We then further divided those images into three different groups based on featured body parts and image resolution: high-resolution facial images (11 images of 7 leopard cats), low-resolution facial images (8 images of 7 individuals), and low-resolution ventral images (7 images of 4 individuals). One low-resolution image was used for matching both facial and ventral parts. We did not have enough high-resolution ventral images to compare individuals, and thus excluded the group in our analysis.

To match individuals, we used HotSpotter, an algorithm for identifying individual animals against a labeled database based on extracting and matching key points and descriptors in the region of interests (Crall et al. 2013). HotSpotter returns the matching result with a score and rank when a reference image is compared with multiple images and correctly matched individuals for

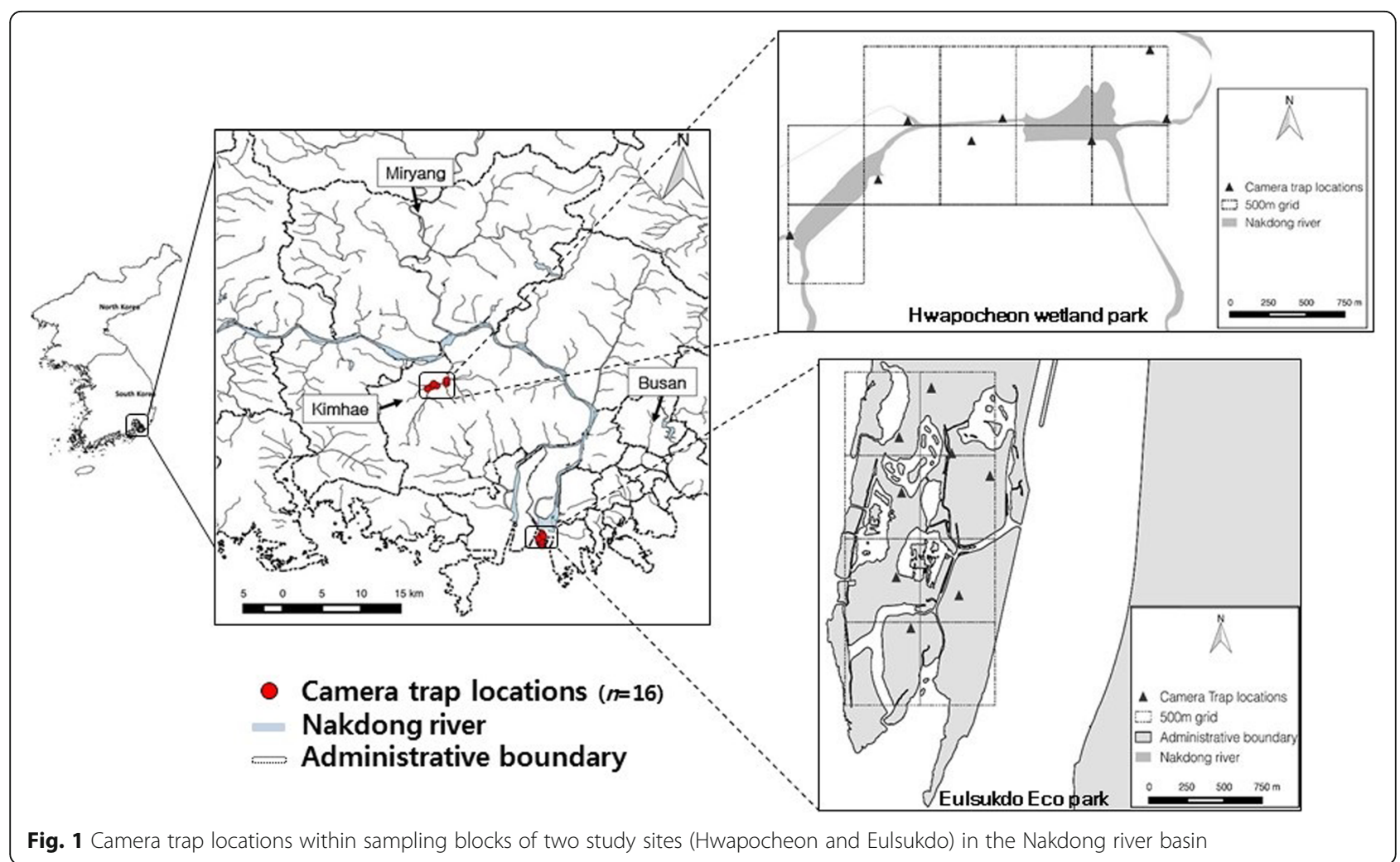




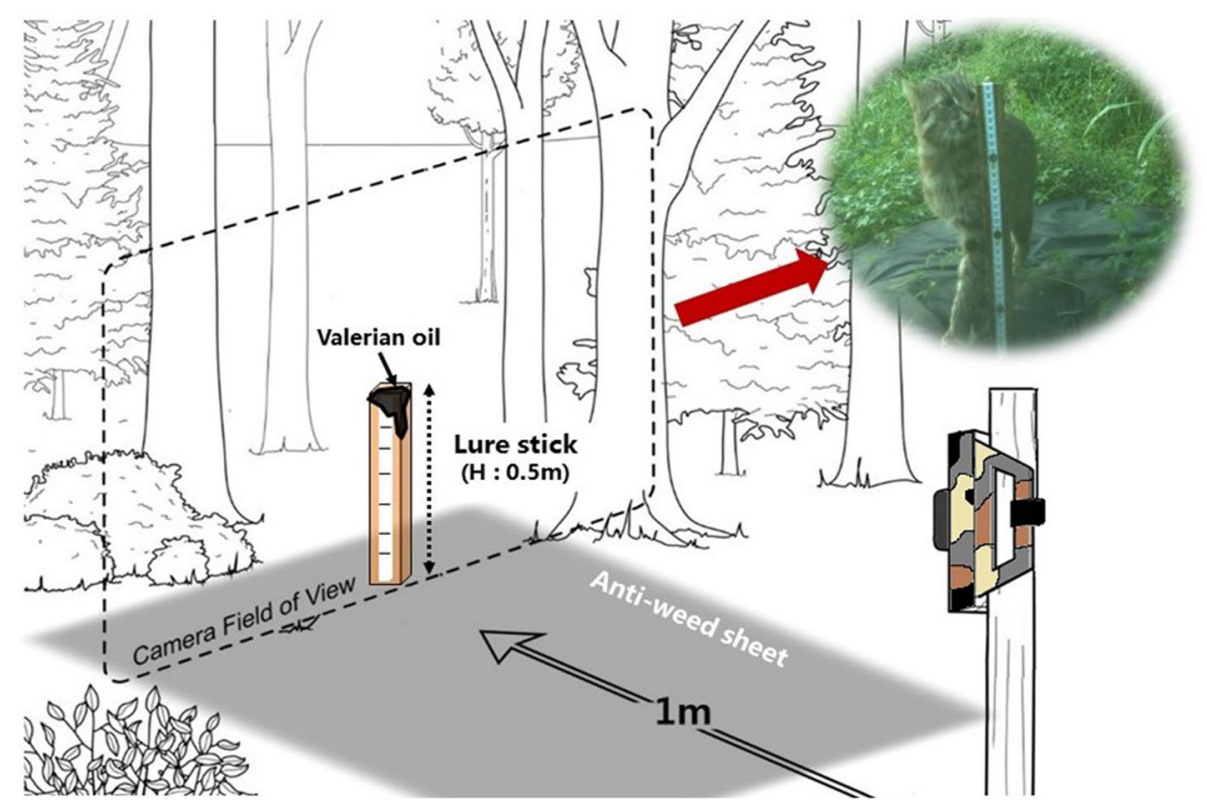

Fig. 2 Survey design of a baited camera trap to effectively capture leopard cat images

95\% of the queries in the previous study which tested the matching individuals of zebras, jaguars, giraffes, and lionfish (Crall et al. 2013). The score, based on the Local Naive Bayes Nearest Neighbor methods, presents the similarity among descriptors of the images and is as low as 0 for non-distinct images (Crall et al. 2013). We first tested the validity of this algorithm by matching a sample facial image (LM.1) of a reference cat with facial images of different species that included a tiger and a leopard. We then matched the sample facial images of a reference leopard cat (LM.1) with a different image (LM.1-1) of that same leopard cat. Further, we matched different leopard cat individuals by comparing coat patterns of their body parts (face and venter) from the selected leopard cat images to each other (Fig. 3). We also tested different image combinations such as containing 0,1 , and 2 images of the same individual to check the changes in scores and ranks in various situations.

\section{Results and discussion}

We confirmed that matching scores of a leopard cat facial image with other species was as low as 0 while the score of matching images of the same leopard cat was 4 , 236,180 in one vs. one matching. In one vs. many matching, HotSpotter correctly top-ranked (rank 0) an image of the same individual leopard cat with the reference leopard cat image $100 \%$ by matching facial and ventral part although matching scores varied from 10 , 838 to $228,151(n=7$, mean $=56,743$, median $=27,181$, $\mathrm{SD}=77,404)$. When there was no matching image with a reference image, rank 0 scores were smaller $(n=11$, score range $=2,571 \sim 28,136$, mean $=12,011$, median $=$
$8,870, \mathrm{SD}=8,870)$ than the scores of having a matched individual (Mann-Whitney $U$ test, $Z=2.75, p<0.01$ ) and often smaller than 10,000 $(n=8)$. Having two images, which matched with a reference image $(n=1)$, those two images were top-ranked, rank 0 and rank 1 respectively. (Note: see the Additional file 1 for the complete matching scores).

Our results indicate that facial and ventral fur patterns of the Amur leopard cat are good matching points to be used reliably to identify individuals although we admit that our small sample size may provide some uncertainty. Comparing the difference in scores between correct matching and incorrect matching, 10,000 in rank 0 was a useful reference score to determine the correct matching in HotSpotter. That is, a matching score around 10,000 needs additional attention before categorizing images. Furthermore, differences in images due to being taken at different angles did not affect the algorithm to match individuals correctly. However, the quality of the image affects the matching success (Gowans and Whitehead 2001; Kelly 2001; Halloran et al. 2015). In computer-based matching, low resolution refers to a small number of pixels available to compare images. Accordingly, low-resolution images, especially when the matching area is small, tended to show low matching scores in our study. Thus, to increase low-resolution image accuracy, we used an anti-weed sheet to reduce image blur and background noise which negatively affect image quality (Halloran et al. 2015). Moreover, we used a bait, Valerian scent stick, to maximize the chance to attract more leopard cats, extend staying time in front of a camera trap, and acquire a clear image of face and 


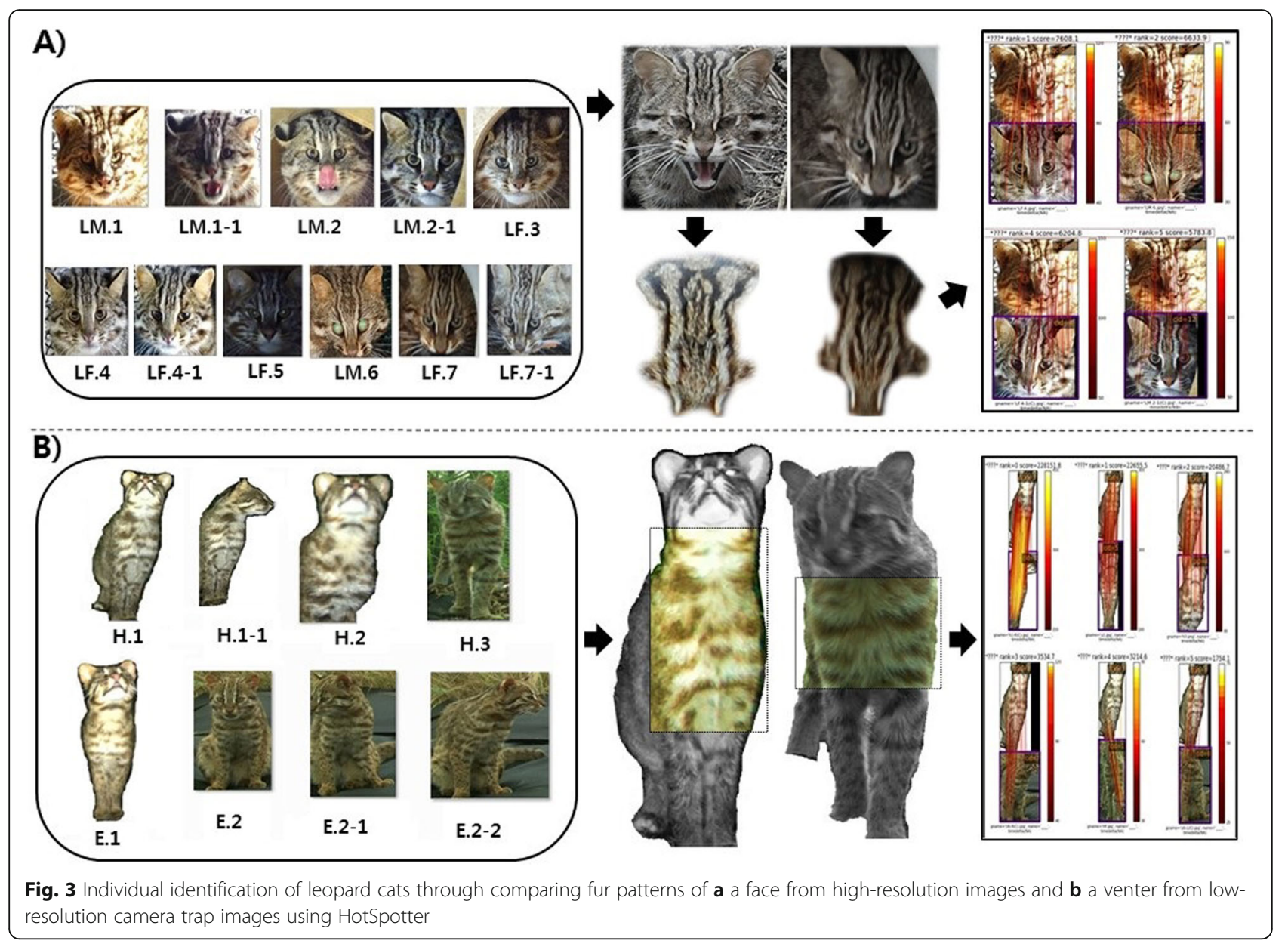

venter of leopard cats. These efforts produced 63 camera trap images of which only 15 images were suitable for matching. Even though the numbers of suitable images were low, our study suggests that using ventral and facial fur patterns is a promising approach for individual identification of Amur leopard cats. However, further testing with increased sample size is beneficial to improve the reliability of the study. Also, research on permanency of facial and ventral fur patterns is necessary to examine the feasibility of using the fur patterns as a lasting natural marking for individual identification because our study proceeded for 6 months. We anticipate that the study result will be useful to researchers interested in studying behavior or population parameter estimates of Amur leopard cats based on capture-recapture models.

\section{Supplementary information}

Supplementary information accompanies this paper at https://doi.org/10. 1186/s41610-019-0138-z.

Additional file 1: Tables S1-S3. Supplementary tables.

\section{Acknowledgements}

The authors would like to thank Tae-Jin Park and Kyung-Sul Yang for assistance with deploying camera tramps and Pao Vue and Vaishnavi Tripuraneni for thoughtful comments on the manuscript.

\section{Authors' contributions}

HP designed the study, carried out the field study, and wrote the manuscript. AL analyzed the data and reviewed/edited the manuscript. TC participated in the design of the study. SB and EG assisted in the field study and analyzed the camera trap photos, and YP reviewed/edited the manuscript. All authors read and approved the final manuscript.

\section{Funding}

This work is part of the National Institute of Ecology (NIE) project (NIEExternal Funding-2015-08), "The Study on the Inhabitation Status of Nutria (Myocastor coypus)" funded by the Ministry of Environment Korea.

\section{Availability of data and materials}

The datasets gathered during and/or analyzed during the current study are available from the corresponding authors on reasonable request.

Ethics approval and consent to participate Not applicable.

Consent for publication Not applicable. 


\section{Competing interests}

The authors declare that they have no completing interests.

\section{Author details}

'Wildlife Research Lab, Kangwon National University, Chuncheon 24341, Republic of Korea. ${ }^{2}$ Research Center for Endangered Species, National Institute of Ecology, Yeongyang 36531, Republic of Korea. ${ }^{3}$ Department of Biology, Jeju National University, Jeju 63243, Republic of Korea. ${ }^{4}$ Division of Ecosystem Assessment, National Institute of Ecology, Seocheon 33657, Republic of Korea.

\section{Received: 29 September 2019 Accepted: 12 November 2019} Published online: 17 December 2019

\section{References}

Alonso RS, McClintock BT, Lyren LM, Boydston EE, Crooks KR. Mark-recapture and mark-resight methods for Estimating abundance with remote cameras: a carnivore case study. Allen BL, editor. PLoS One. 2015;10(3):e0123032.

Anderson CJR, Roth JD, Waterman JM. Can whisker spot patterns be used to identify individual polar bears? J Zool. 2007;273(4):333-9.

Anile S, Arrabito C, Mazzamuto MV, Scornavacca D, Ragni B. A non-invasive monitoring on European wildcat (Felis silvestris silvestris Schreber, 1777) in Sicily using hair trapping and camera trapping: does scented lure work? Hystrix. 2012;23(2):1.

Avgan B, Zimmermann F, Güntert M, Arıkan F, Breitenmoser U. The first density estimation of an isolated Eurasian lynx population in southwest asia. Wildlife Biol. 2014;20(4):217-21.

Bashir T, Bhattacharya T, Poudyal K, Sathyakumar S, Qureshi Q. Estimating leopard cat Prionailurus bengalensis densities using photographic captures and recaptures. Wildlife Biol. 2013;19(4):462-72.

Boron V, Tzanopoulos J, Gallo J, Barragan J, Jaimes-Rodriguez L, Schaller G, Payán E. Jaguar Densities across human-dominated landscapes in Colombia: the contribution of unprotected areas to long term conservation. PLoS One. 2016;11(5):e0153973.

Burki S, Roth T, Robin K, Weber D. Lure sticks as a method to detect pine martens Martes martes. Acta Theriol (Warsz). 2010;55(3):223-30.

Caravaggi A, Banks PB, Burton AC, Finlay CMV, Haswell PM, Hayward MW, Rowcliffe MJ, Wood MD. A review of camera trapping for conservation behaviour research. Pettorelli N, Sollmann R, editors. Remote Sens Ecol Conserv. 2017;3(3):109-22.

Crall JP, Stewart C V., Berger-Wolf TY, Rubenstein DI, Sundaresan SR. HotSpotterpatterned species instance recognition. Proc IEEE Work Appl Comput Vis. IEEE; 2013;230-237.

Creel S, Creel NM. Lion density and population structure in the Selous Game Reserve: evaluation of hunting quotas and offtake. Afr J Ecol. 1997;35(2):8393.

Cullen L, Abreu KC, Sana D, Dales AF. Jaguars as landscape detectives for the upper paraná River Corridor. Brazil. J Nat Conserv. 2005;3(April 2005):43-58.

Gompper ME, Kays RW, Ray JC, LaPoint SD, Bogan DA, Cryan JR. A comparison of non-invasive techniques to survey carnivore communities in Northeastern North America. Wildl Soc Bull. 2006;34(4):1142-51.

Gowans S, Whitehead H. Photographic identification of northern bottlenose whales (Hyperoodon ampullatus): sources of heterogeneity from natural marks. Mar Mammal Sci. 2001:17(1):76-93.

Halloran KM, Murdoch JD, Becker MS. Applying computer-aided photoidentification to messy datasets: a case study of Thornicroft's giraffe (Giraffa camelopardalis thornicrofti). Afr J Ecol. 2015;53(2):147-55.

Henschel P, Ray J. Leopards in African rainforests : survey and monitoring techniques. WCS Glob. Carniv. Progr. 2003.

Jenks KE, Chanteap P, Damrongchainarong $K$, Cutter P, Cutter P, Redford T, Lynam7 AJ, Howard J, Leimgruber P. Using relative abundance indices from camera-trapping to test wildlife conservation hypotheses - an example from Khao Yai National Park, Thailand. Trop Conserv Sci. 2011;4(2):113-131.

Jones JPG. Monitoring species abundance and distribution at the landscape scale. J Appl Ecol. 2011:48(1):9-13.

Karanth KU, Chundawat RS, Nichols JD, Kumar NS. Estimation of tiger densities in the tropical dry forests of Panna, Central India, using photographic capturerecapture sampling. Anim Conserv. 2004;7(3):285-90.

Karanth KUU, Nichols JD. Estimation of tiger densities in India using photographic captures and recaptures. Ecology. 1998;79(8):2852-62.
Karki JB, Pandav B, Jnawali SR, Shrestha R, Pradhan NMB, Lamichane BR, Khanal P, Subedi N, Jhala Y V. Estimating the abundance of Nepal's largest population of tigers Panthera tigris. Oryx. 2013;FirstView(October 2012):1-7.

Kelly MJ. Computer-aided photograph matching in studies using individual identification: an example from Serengeti cheetahs. J Mammal. 2001;82(2): 440-9.

Linden DW, Fuller AK, Royle JA, Hare MP. Examining the occupancy-density relationship for a low-density carnivore. J Appl Ecol. 2017;54(6):2043-52.

Lynam AJ, Rabinowitz A, Myint T, Maung M, Latt KT, Po SHT. Estimating abundance with sparse data: tigers in northern Myanmar. Popul Ecol. 2009; 51(1):115-21.

Maffei L, Noss AJ. How small is too small? Camera trap survey areas and density estimates for ocelots in the Bolivian Chaco. Biotropica. 2008;40(1):71-5.

McCarthy KP, Fuller TK, Ming M, McCarthy TM, Waits L, Jumabaev K. Assessing estimators of snow leopard abundancE. J Wildl Manage. 2008:72(8):1826-33.

Mettouris $\mathrm{O}$, Megremis G, Giokas S. A newt does not change its spots: using pattern mapping for the identification of individuals in large populations of newt species. Ecol Res. 2016;31(3):483-9.

Ministry of Environment. Wild life protection and management act. ACT No. 15835 Rep. of Korea; 2011.

Nichols JD. Capture-Recapture Models. Bioscience. 1992;42(2):94-102.

Osterrieder SK, Kent CS, Anderson CJR, Parnum IM, Robinson RW. Whisker spot patterns: a noninvasive method of individual identification of Australian sea lions (Neophoca cinerea). J Mammal. 2015;96(5):988-97.

Park H, Lim A, Choi T-Y, Lim S-J, Park Y-C. Estimating population density of leopard cat (Prionailurus bengalensis) from camera traps in Maekdo Riparian Park. South Korea. J For Environ Sci. 2017;33(3):239-42.

Qi J, Shi Q, Wang G, Li Z, Sun Q, Hua Y, Jiang G. Spatial distribution drivers of Amur leopard density in northeast China. Biol Conserv. Elsevier B.V.; 2015;191: 258-265.

Ross J, Brodie J, Cheyne S, Hearn A, Izawa M, Loken B, Lynam A, McCarthy J, Mukherjee S, Phan C, Rasphone A, Wilting A, Ross J, Brodie J, Cheyne S, Hearn A, Izawa M, Loken B, Lynam A, McCarthy J, Mukherjee S, Phan C, Rasphone A, Wilting A. Prionailurus bengalensis. IUCN Red List Threat. Species. 2015;2015.

Rovero F, Martin E, Rosa M, Ahumada JA, Spitale D. Estimating species richness and modelling habitat preferences of tropical forest mammals from camera trap data. PLoS One. 2014;9(7).

Royle JA, Young KV. A hierarchical model for spatial capture recapture data. Ecology. 2008;89(8):2281-9.

Russell RE, Royle JA, Desimone R, Schwartz MK, Edwards VL, Pilgrim KP, McKelvey KS. Estimating abundance of mountain lions from unstructured spatial sampling. J Wildl Manage. 2012;76(8):1551-61.

Seber GAF. The estimation of animal abundance and related parameters. New York, NY, USA: Hafner Press; 1973.

Sharma S, Dutta T, Maldonado JE, Wood TC, Panwar HS, Seidensticker J. Spatial genetic analysis reveals high connectivity of tiger (Panthera tigris) populations in the Satpura-Maikal landscape of Central India. Ecol Evol. 2013; 3(1):48-60

Sirén A, Pekins P, Abdu P, Ducey M. Identification and density estimation of American Martens (Martes americana) using a novel camera-trap method. Diversity. 2016;8(4):3.

Soisalo MK, Cavalcanti SMC. Estimating the density of a jaguar population in the Brazilian Pantanal using camera-traps and capture-recapture sampling in combination with GPS radio-telemetry. Biol Conserv. 2006;129(4):487-96.

Steyer K, Simon O, Kraus RHS, Haase P, Nowak C. Hair trapping with valeriantreated lure sticks as a tool for genetic wildcat monitoring in low-density habitats. Eur J Wild Res. 2013;59(1):39-46.

Tobler MW, Carrillo-Percastegui SE, Leite Pitman R, Mares R, Powell G. An evaluation of camera traps for inventorying large- and medium-sized terrestrial rainforest mammals. Anim Conserv. 2008;11(3):169-78.

\section{Publisher's Note}

Springer Nature remains neutral with regard to jurisdictional claims in published maps and institutional affiliations. 